\title{
A Wavelet-Based Area Parameter for Indirectly Estimating Copper Concentration in Carex Leaves from Canopy Reflectance
}

\author{
Junjie Wang ${ }^{1}$, Tiejun Wang ${ }^{2}$, Tiezhu Shi ${ }^{1}$, Guofeng Wu ${ }^{1, *}$ and Andrew K. Skidmore ${ }^{2}$
}

1 Key Laboratory for Geo-Environmental Monitoring of Coastal Zone of the National Administration of Surveying, Mapping and Geo-Information \& Shenzhen Key Laboratory of Spatial-temporal Smart Sensing and Services \& College of Life and Marine Sciences, Shenzhen University, Shenzhen 518060, China; E-Mails: wjjlight@163.com (J.W.); tiezhushi@whu.edu.cn (T.S.)

2 Faculty of Geo-Information Science and Earth Observation (ITC), University of Twente, P.O. Box 217, 7500-AE Enschede, The Netherlands; E-Mails: t.wang@utwente.nl (T.W.); a.k.skidmore@utwente.nl (A.K.S.)

* Author to whom correspondence should be addressed; E-Mail: guofeng.wu@ szu.edu.cn; Tel.: +86-755-2693-3149.

Academic Editors: Yoshio Inoue and Prasad S. Thenkabail

Received: 31 July 2015 / Accepted: 12 November 2015 / Published: 17 November 2015

\begin{abstract}
Due to the absence of evident absorption features and low concentrations, the copper $(\mathrm{Cu})$ concentration in plant leaves has rarely been estimated from hyperspectral remote sensing data. The capability of remotely-sensed estimation of foliar $\mathrm{Cu}$ concentrations largely depends on its close relation to foliar chlorophyll concentration. To enhance the subtle spectral changes related to chlorophyll concentration under $\mathrm{Cu}$ stress, this study described a wavelet-based area parameter ( $\mathrm{S}_{\mathrm{WT}}(605-720)$, the sum of reconstructed detail reflectance at fourth decomposition level over $605-720 \mathrm{~nm}$ using discrete wavelet transform) from the canopy hyperspectral reflectance $(350-2500 \mathrm{~nm}, N=71)$ of Carex $(C$. cinerascens). The results showed that $\mathrm{Cu}$ concentrations had negative and strong correlation with chlorophyll concentrations $(r=-0.719, p<0.001)$. Based on 1000 random dataset partitioning experiments, the 1000 linear calibration models provided a mean $\mathrm{R}^{2}$ val (determination coefficient of validation) value of 0.706 and an RPD (residual prediction deviation) value of 1.75 for $\mathrm{Cu}$ estimation. The bootstrapping and ANOVA test results showed that $\mathrm{S}_{\mathrm{WT}}$ (605-720) significantly $(p<0.05)$ outperformed published chlorophyll-related and wavelet-based spectral parameters. It was concluded here that the wavelet-based area parameter (i.e., SWT (605-720)) has potential ability to indirectly estimate
\end{abstract}


$\mathrm{Cu}$ concentrations in Carex leaves through the strong correlation between $\mathrm{Cu}$ and chlorophyll. The method presented in this pilot study may be used to estimate the concentrations of other heavy metals. However, further research is needed to test its transferability and robustness for estimating $\mathrm{Cu}$ concentrations on other plant species in different biological and environmental conditions.

Keywords: canopy reflectance; foliar chlorophyll concentration; foliar copper concentration; hyperspectral remote sensing; spectral parameter; wavelet transform

\section{Introduction}

A certain amount of heavy metals (e.g., copper) in plants is essential for building enzymes and proteins, which are beneficial to plant growth and development [1]. However, the uptake of excessive heavy metals from contaminated soils, waste water, or road dusts may disrupt the homeostatic mechanism of plant photosynthesis and stimulate the formation of oxidative stress, resulting in leaf injury, growth inhibition, and yield reduction [1-4]. In terrestrial ecosystems, the concentration of heavy metals in plant leaves is an important indicator of pollution status in surrounding environment [5,6]. It is, therefore, important to monitor the spatial and temporal dynamics of heavy metal concentrations in leaves for early warning of heavy metal pollution and understanding the ecosystem responses to heavy metal variations in specific environments.

Hyperspectral remote sensing is a valid alternative to traditional ground-based methods, and it has been widely used to quantify the biophysical (e.g., leaf area index and net primary productivity) [7] and biochemical (e.g., chlorophyll and nitrogen) [8-10] properties of plants at the leaf, canopy, and landscape levels. Numerous studies have focused on the retrieval of the spectrally active biochemical properties of plants (e.g., water, chlorophyll, and nitrogen) using physical or statistical models [8-20]. In contrast, much less progress has been made to estimate foliar heavy metal concentrations [21-25], which may be due to their very low concentrations in plant leaves (e.g., normally $5-30 \mathrm{mg} \cdot \mathrm{kg}^{-1}$ for $\mathrm{Cu}$ ) [26] and absence of evident physical absorption features existing for major constituents (e.g., water, chlorophyll, and starch) [27]. This makes it impossible to predict heavy metal concentrations directly from hyperspectral data. Several studies with controlled experiments have found that chlorophyll concentrations in plant leaves tend to decrease with increasing heavy metal stress levels [4,23]. The reason for this relationship is that heavy metals are known to interfere with chlorophyll synthesis $[4,28]$. Consequently, the heavy metal stress in plant leaves would characteristically change the leaf reflectance spectrum, such as increasing reflectance over visible wavebands, decreasing reflectance over near-infrared wavebands and shifting the red edge position to shorter wavebands [23,29]. Hence, heavy metal concentrations could be theoretically predicted by capturing the indirect change of reflectance spectra caused by the decrease of chlorophyll concentration in plant leaves.

In order to effectively capture the abovementioned change of reflectance spectra under heavy metal stress, some spectral parameters, such as vegetation index [22], band depth parameter [24], and position parameter [23,24], were employed for foliar heavy metal estimation. However, none of these studies have attempted to derive an area parameter (the sum of reflectance over a sensitive spectral 
region) from vegetation reflectance spectra. This parameter can cover more spectral information than two-band or three-band vegetation index, and it has been proven to provide a more highly accurate model than position parameters [30]. Delegido et al. [18] demonstrated the successful application of an area parameter in estimating foliar chlorophyll concentrations of heterogeneous crops. For this reason, area parameters may be suitable for quantifying trace heavy metals without evident absorption features.

Under natural conditions, heavy metal concentrations in plant leaves might not be high enough to trigger the significant change of vegetation reflectance spectra, hence, a method that can be used to enhance the potential subtle spectral changes is needed. Several studies have employed wavelet transform (WT) to overcome this problem [22,31], because WT can preserve the peaks and valleys among spectral signatures and magnify subtle spectral features [22,32]. WT breaks up a signal into a set of shifted and scaled versions of the original (or mother) wavelet, resulting in approximation (low-pass filter) coefficients and detail (high-pass filter) coefficients at various decomposition levels [33,34]. WT also has good performances in spectral denoising and smoothing [35] and spectral dimension reduction [36]. WT has been used successfully in many fields of remote sensing, such as image processing [37], identification of vegetation [38], mapping [39], and quantification of biochemical parameters in plant leaves, such as chlorophyll concentration [9,40], water content [15], and heavy metal concentrations [22].

The spectral parameters used for quantifying biophysical and biochemical properties of plants are generally derived from original, derivative, or continuum-removed reflectance. Few of the previous studies have documented spectral parameters (especially area parameters) derived from the WT analysis of vegetation reflectance. Liu et al. [22] were the first to attempt to estimate $\mathrm{Cu}$ and $\mathrm{Cd}$ concentrations in rice leaves using a wavelet-based spectral parameter. However, this type of estimation is still at the exploratory stage and requires more investigation and test with other species. Further, the methodology of developing a wavelet-based spectral parameter, such as how to select the optimal decomposition level and extract the optimal spectral region for area parameter construction, has not been well described for reference in existing studies.

With samples and reflectance spectra of plants collected under field conditions, this study aimed to (i) explore the relationship between $\mathrm{Cu}$ and chlorophyll concentration in Carex (C. cinerascens) leaves, (ii) describe a wavelet-based area parameter from canopy reflectance of Carex to enhance the subtle spectral changes related to chlorophyll concentration under $\mathrm{Cu}$ stress, and use it to indirectly estimate foliar $\mathrm{Cu}$ concentrations, and (iii) compare the performance of the wavelet-based area parameter to that of some classical chlorophyll-related and wavelet-based spectral parameters in $\mathrm{Cu}$ estimation.

\section{Materials}

\subsection{Study Area}

The study area is located in Poyang Lake $\left(28^{\circ} 52^{\prime} 21^{\prime \prime} \mathrm{N}-29^{\circ} 06^{\prime} 46^{\prime \prime} \mathrm{N}, 116^{\circ} 10^{\prime} 24^{\prime \prime} \mathrm{E}-116^{\circ} 23^{\prime} 50^{\prime \prime} \mathrm{E}\right)$, China (Figure 1a). Poyang Lake is the largest fresh lake in China. Carex (C. cinerascens) is the dominant wetland species in Poyang Lake, and it is the main food source of many over-wintering birds 
such as swan goose (Anser cygnoides) and white-fronted goose (A. albifrons albifrons) [41]. There are several metal mining regions at the side of Poyang Lake, such as Dexing and Yongping Cu mines [42]. The mining activities bring relatively high concentrations of $\mathrm{Cu}$ into water and sediment of Poyang Lake [42], which may significantly impact the growth of wetland plants (e.g., Carex).

(a)

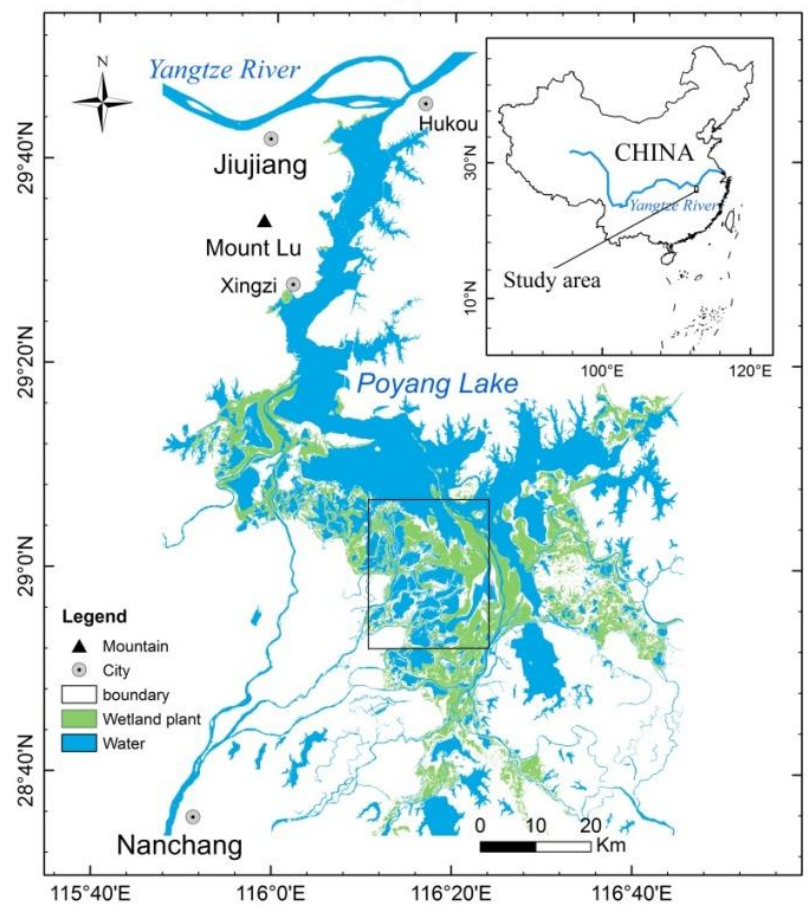

(b)

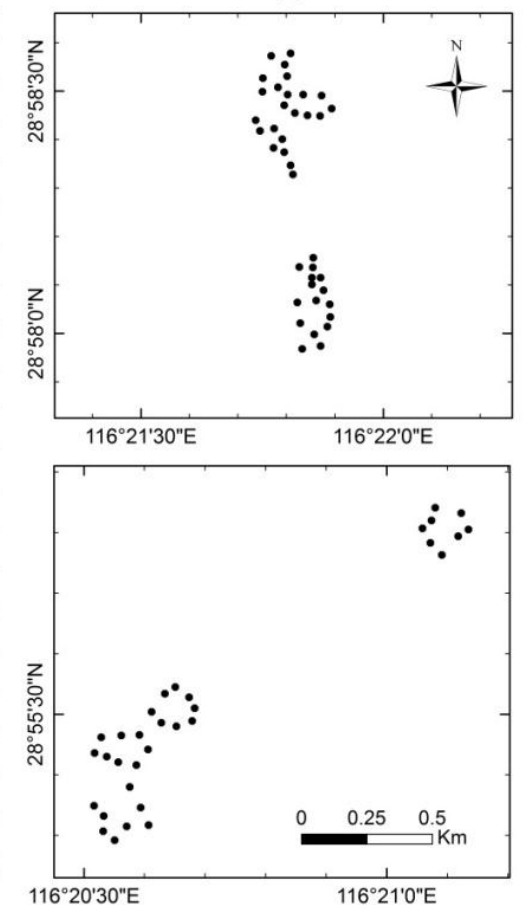

Figure 1. (a) Location of the study area in Poyang Lake, China and (b) the spatial distribution of 71 Carex samples.

\subsection{Data Collection}

The fieldwork was conducted during April 2013 in Poyang Lake. A total of nine sites $(150 \times 150 \mathrm{~m})$ were randomly selected (Figure $1 \mathrm{~b})$, covering 71 plots $(1 \times 1 \mathrm{~m})$ with large areas containing Carex communities. Any two plots were at least $30 \mathrm{~m}$ apart. At each plot, canopy reflectance measurements (350-2500 nm) were made using an ASD FieldSpec ${ }^{\circledR} 3$ portable spectroradiometer (Analytical Spectral Devices, Inc., Boulder, CO, USA) with a field of view of $10^{\circ}$. Before each spectral measurement, calibrated reflectance measurements were taken using a white Spectralon panel to minimize the effects of changes in solar irradiance and atmospheric conditions on canopy reflectance. At each plot, 10 successive spectra were measured at the nadir position from $1 \mathrm{~m}$ above the canopy, and their mean values were calculated and recorded as the canopy reflectance spectra. After each spectral measurement, a portable chlorophyll meter (SPAD-502, Minolta Camera Co. Ltd., Osaka, Japan) was used to measure the SPAD readings of Carex samples. During each measurement, direct sunlight was avoided by the operator, and a total of 20 green leaves were randomly measured and averaged as the final SPAD value. Afterwards, five subplots $(0.25 \times 0.25 \mathrm{~m})$ in the four corners and center of each plot were harvested by clipping leaves $(5 \mathrm{~cm}$ above the ground) and pooled, and the pooled fresh leaves were immediately put into a labeled sample bag and sent to laboratory for their chemical analyses. 
Numerous studies have demonstrated the strong correlation between foliar chlorophyll concentration and SPAD-502 chlorophyll readings [43]. In this study, the chlorophyll concentration (unit: $\mathrm{mg} \cdot \mathrm{g}^{-1}$ ) of each plot was calculated by the following equation developed by Uddling et al. [43]:

$$
Y_{C h l}=0.363 e^{0.0452 x}
$$

Where $\mathrm{Y}_{\mathrm{Chl}}$ is chlorophyll concentration and $\mathrm{x}$ is SPAD value.

The collected fresh leaves were cleaned using distilled water to remove soil and dead leaves, air-dried at room temperature for $24 \mathrm{~h}$, dried at $70{ }^{\circ} \mathrm{C}$ for $24 \mathrm{~h}$ in an oven, ground with an agate mortar, and passed through a 65 -mesh sieve $(0.25 \mathrm{~mm})$. The ground samples were then pre-processed with $\mathrm{HNO}_{3}-\mathrm{H}_{2} \mathrm{SO}_{4}-\mathrm{HCLO}_{4}$ using the microwave digestion method. The $\mathrm{Cu}$ concentrations (unit: $\mathrm{mg} \cdot \mathrm{kg}^{-1}$ ) were determined with an AA-6601F Flame Atomic Absorption Spectrometry (FFAS) according to the Chinese National Standards GB3838-2002 [44]. To ensure measurement accuracy, certified reference materials and reagent blanks were used during chemical analyses.

\subsection{Spectral Pre-Processing}

The 71 canopy reflectance spectra $(350-2500 \mathrm{~nm})$ were first reduced to $400-1350 \mathrm{~nm}$ because of noises at both edges $(<399 \mathrm{~nm}$ and $>2400 \mathrm{~nm})$ and the strong water absorption regions centered at 1400 and $1940 \mathrm{~nm}$. According to the findings reported by Blackburn and Ferwerda [9], first derivative reflectance spectra can be more suitable as input for WT analysis than original reflectance spectra, due to the strengthening of feature peaks and valleys by derivative analysis. The reduced spectra were then subjected to first derivative analysis with the Savitzky-Golay smoothing method to minimize the impact of soil background and multiple scattering of radiation on canopy reflectance spectra $[9,10]$.

\section{Methods}

\subsection{Selection of Mother Wavelet Function for Wavelet Transform}

A wavelet $\psi(\lambda)$ is an oscillating waveform function with an average value of zero $\left(\int_{-\infty}^{+\infty} \psi(\lambda) d \lambda=0\right)$ [33]. Wavelet transform (WT) decomposes a signal $s(\lambda)$ into dilated (scaled) and continuous WT (CWT)) or dyadic (corresponding to discrete WT (DWT)) scales [33,34]. The wavelet decomposition, thus, yields a series of wavelet coefficients $C(a, b)$ :

$$
C(a, b)=\int_{-\infty}^{+\infty} s(\lambda) \frac{1}{\sqrt{a}} \psi\left(\frac{\lambda-b}{a}\right) d \lambda
$$

Here, $a$ and $b$ are scale (spectral width) and position parameters, respectively. For CWT, $a \in R^{+}$and $b \in R$. For DWT, $a=2^{j}, b=k 2^{j},(j, k) \in Z^{2}$, and $\mathrm{j}$ is the decomposition level.

From the space-saving perspective of wavelet decomposition (Equation (2)), it is computationally expensive for CWT but efficient for DWT. Furthermore, DWT is also sufficient for exact reconstruction to ensure the same dimension as the original signal, and it can preserve general traits and magnify subtle features [39,40,45]. For this reason, DWT was used for hyperspectral signal decomposition and reconstruction, and it was implemented using the Wavelet Toolbox (Version 4.6) of Matlab 2010b (The MathWorks, Inc., Natick, MA, USA). 
From the uncertainty perspective of wavelet decomposition (Equation (2)), the wavelet coefficients vary with different mother wavelet functions. There are more than 50 mother wavelet functions used in various studies, and there is no single or generally accepted criterion for choosing an appropriate wavelet function for DWT $[9,33,38,40,45]$. Among these mother wavelet functions, the Daubechies wavelet ( $\mathrm{db} N, N$ is the order) has been widely used for signal analysis, because it can detect the discontinuity in vibration signals and provide compact support and orthogonal wavelets [38,45]. Considering the findings of Liu et al. [31] and Koger et al. [38], db5 was here used as the mother wavelet function, mainly due to its ability in amplifying vegetation stress information. The db5 wavelet is an orthogonal wavelet with the characteristics of compact support, symmetry and smoothness, and its accuracy of signal reconstruction is high with little phase distortion [33,34].

\subsection{Spectral Decomposition and Reconstruction Using Discrete Wavelet Transform}

The decomposition of DWT was implemented using a dyadic filter tree with down-sampling and filtering (Figure 2). The original signal is passed through a series of high-pass and low-pass filters. The low-pass component provides an approximation of signal, reflecting the general features. The high-pass component provides the detail of signal, reflecting the subtle features. This hierarchical decomposition results in the dyadic decrease of dimension for both approximation and detail coefficients.

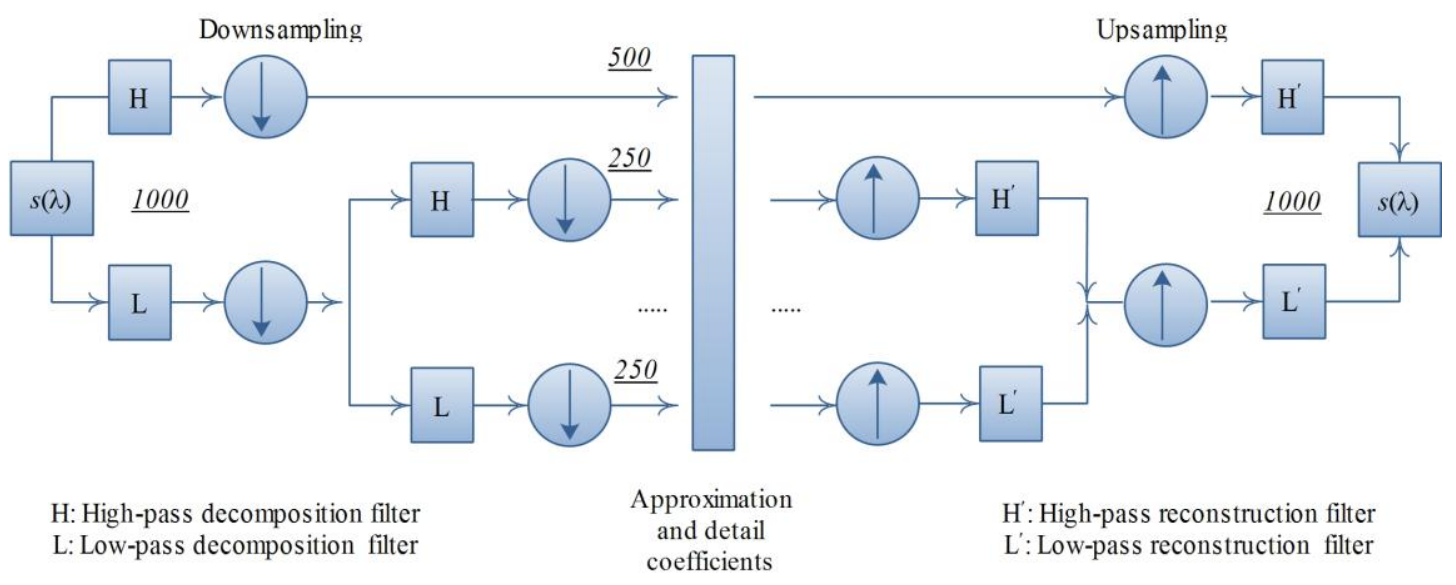

Figure 2. Decomposition and reconstruction processes of discrete wavelet transform (DWT) (The figure was adapted based on the original figure in Misiti et al. [33]).

The approximation and detail reflectance can be reconstructed from their coefficient vectors by up-sampling and filtering. The reconstruction process was performed as described by Misiti et al. [33]. This reconstruction provides the same dimension as the original spectral signal, which is beneficial for further spectral analysis [22].

\subsection{Defining a Wavelet-Based Area Parameter Using Discrete Wavelet Transform}

As mentioned in the Introduction, the purpose of this study was to define a wavelet-based area parameter $\left(\mathrm{S}_{\mathrm{WT}}\left(\lambda 1-\lambda_{2}\right)\right.$ ) (Figure 3 ) for estimating $\mathrm{Cu}$ concentration in Carex leaves, because WT can 
magnify subtle spectral signatures of biophysical and biochemical components. Three steps were taken to achieve this goal:

1. Selection of the optimal decomposition level for DWT analysis of pre-processed reflectance (i.e., first derivative reflectance);

2. Rough identification of the spectral region $(\lambda 1-\lambda 2 \mathrm{~nm})$ sensitive to foliar $\mathrm{Cu}$ variations;

3. Optimization of the spectral region for the area parameter.

For the first step, two simple rules were proposed:

(1) The reconstructed approximation reflectance was required to maximize the spectral similarity of first derivative reflectance to ensure the general shape and localization of spectral features;

(2) The reconstructed detail reflectance required maximizing the correlation with foliar $\mathrm{Cu}$ concentrations to magnify the subtle spectral information.

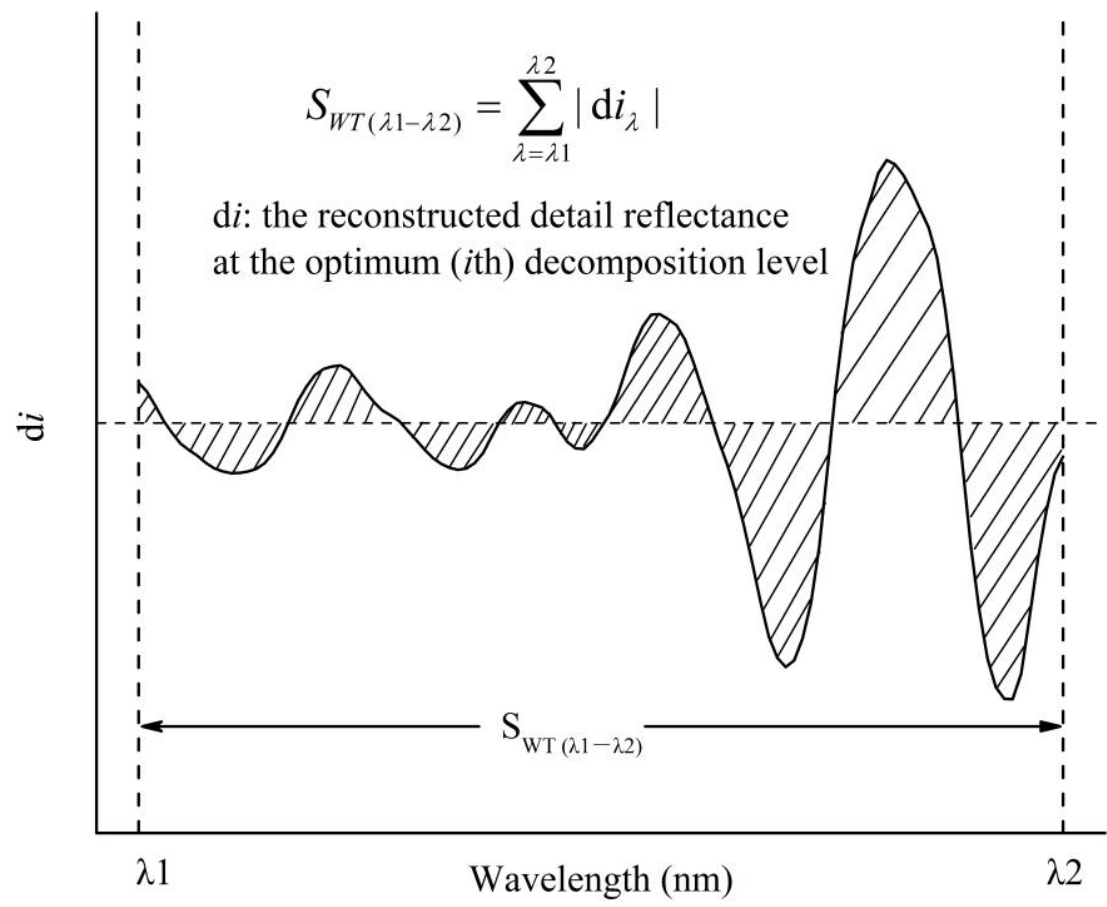

Figure 3. Wavelet-based area parameter $\mathrm{S}_{\mathrm{WT}}(\lambda 1-\lambda 2)$ (absolute area).

The spectral similarity analysis was performed for each sample using Minkowski distance ( $\left.D_{\text {Mink }}\right)$. The $D_{\text {Mink }}$ between first derivative reflectance $\left(D_{\lambda}\right)$ and reconstructed approximation reflectance $\left(A_{\lambda}\right)$ for each wavelength $\lambda(400-1350 \mathrm{~nm})$ is given as follows [46]:

$$
D_{\text {Mink }}=\left(\sum_{\lambda=400}^{1350}\left(D_{\lambda}-A_{\lambda}\right)^{2}\right)^{\frac{1}{2}}
$$

For each sample, $D_{\text {Mink }}$ between $D_{\lambda}$ and $A_{\lambda}$ at different decomposition levels (a1, a2, a3, a4, a5, a6, a7 and a8) was calculated, respectively. Correlation analysis was implemented using the maximum absolute Pearson's correlation coefficient $(r)$ between $\mathrm{Cu}$ concentration and reconstructed detail reflectance at different decomposition levels (d1, d2, d3, d4, d5, d6, d7 and d8). 
For the second step, the foliar $\mathrm{Cu}$ concentrations of 71 samples were first classified into three groups based on the findings of Kabata-Pendias and Pendias [26]: safe level $\left(0-30 \mathrm{mg} \cdot \mathrm{kg}^{-1}\right)$, low pollution $\left(30-60 \mathrm{mg} \cdot \mathrm{kg}^{-1}\right)$, and moderate pollution $\left(60-120 \mathrm{mg} \cdot \mathrm{kg}^{-1}\right)$. For each group, the mean reconstructed detail reflectance at the optimum decomposition level was calculated and plotted, respectively. The sensitive spectral region $(\lambda 1-\lambda 2 \mathrm{~nm})$ was roughly determined by observing whether the amplitudes of mean reflectance accorded with the increasing mean $\mathrm{Cu}$ concentrations for the three groups.

For the third step, the appropriate spectral region was optimized by calculating the Pearson's correlation coefficient $(r)$ between foliar $\mathrm{Cu}$ concentrations and SWT $(\lambda 1-\lambda 2)$ with different adjacent spectral regions. Specifically, $\lambda 1$ first remained unchanged while $\lambda 2$ was changed into $\lambda 2+k \times 5$ $(k=1,2, \ldots, 10)$, and then $\lambda 2$ remained unchanged while $\lambda 1$ was changed into $\lambda 1-k \times 5(k=1,2, \ldots, 10)$, respectively. The area parameter with the maximum $r$ against foliar $\mathrm{Cu}$ concentration was considered as the optimum area parameter, which was further used for foliar $\mathrm{Cu}$ estimation.

\subsection{Estimation of Foliar Cu Concentration Using the Wavelet-Based Area Parameter}

For reliable quantification of foliar $\mathrm{Cu}$ concentration, the dataset $\left(\mathrm{Cu}\right.$ concentration and $\mathrm{S}_{\mathrm{WT}}(\lambda 1-\lambda 2)$, $N=71)$ was randomly split into calibration set $(N=36)$ and validation set $(N=35)$ by 1000 times, resulting in 1000 different calibration and validation sets. Each of the 1000 linear calibration models $\left(Y=k \times S_{W T(\lambda 1-\lambda 2)}+b\right)$ was calibrated with the calibration set, and then independently validated with the corresponding validation set. The root mean square error of calibration (RMSECal) and validation (RMSEVal), the determination coefficient of calibration $\left(\mathrm{R}^{2} \mathrm{Cal}\right)$ and validation $\left(\mathrm{R}^{2} \mathrm{val}\right)$ and residual prediction deviation (RPD, the ratio of standard deviation to RMSEVal) values were calculated to evaluate the performance of each model. The $\mathrm{R}^{2}$ val and RPD values indicate the quality and predictive power of the calibration $n$ models, respectively. The statistics of model equation parameters ( $k$ and $b$ ), RMSECal, $\mathrm{R}^{2} \mathrm{Cal}, \mathrm{RMSEVal}, \mathrm{R}^{2}$ Val, and RPD values for the 1000 models were reported.

In order to explore the ability of $\mathrm{S}_{\mathrm{WT}}\left(\lambda_{1-\lambda 2)}\right.$ in estimating $\mathrm{Cu}$ concentrations, the general calibration model using the mean $k$ and $b$ values was employed with the full dataset $(N=71)$, and measured against the predicted values, which were then plotted. Moreover, the mean absolute relative error $\left(\mathrm{MARE}=\left(\sum \mid\right.\right.$ predicted value - measured value $/$ measured value $\left.) / N\right)$ was calculated for the three concentration groups (safe level, low pollution, and moderate pollution), respectively.

\subsection{Performance Comparison between the Wavelet-Based Area Parameter and Published Spectral Parameters}

In order to check the practicality of the wavelet-based area parameter ( $\mathrm{SWT}_{\mathrm{WT}}(605-720)$ ), its performance was compared to that of ten classical chlorophyll-related spectral parameters (Table 1 [11,13,14,16-20,30,47]) and one published wavelet-based spectral parameter (FDWT $480-850$, the fractal dimension of reflectance with wavelet transform using detail reflectance at the fifth decomposition level in the region of 480-850 nm) [22] using the bootstrapping method with 1000 replicates. Bootstrapping provided the estimates of statistics (mean and confidence intervals) for the determination coefficient $\left(\mathrm{R}^{2}\right)$ for estimating foliar $\mathrm{Cu}$ concentrations with the 12 spectral parameters (including $\mathrm{S}_{\mathrm{WT}}$ (605-720)) using the full dataset $(N=71)$. In addition, one-way ANOVA (analysis of variance) using the least squares 
difference (LSD) method was performed to determine whether there were significant differences in the mean $\mathrm{R}^{2}$ between $\mathrm{S}_{\mathrm{WT}}$ (605-720) and the aforementioned 11 chlorophyll-related and wavelet-based spectral parameters.

Table 1. Some classical chlorophyll-related spectral parameters. ${ }^{\text {a }}$

\begin{tabular}{|c|c|c|}
\hline Spectral Parameter & Formula & Reference \\
\hline $\begin{array}{l}\text { Modified simple ratio (MSR } \\
[670,800])\end{array}$ & $\frac{\left(\rho_{800} / \rho_{670}\right)-1}{\sqrt{\left(\rho_{800} / \rho_{670}\right)+1}}$ & Chen [17] \\
\hline $\begin{array}{l}\text { Modified simple ratio (MSR } \\
[500,720])\end{array}$ & $\frac{\rho_{720}^{\prime}-\rho_{500}^{\prime}}{\rho_{700}^{\prime}-\rho_{500}^{\prime}}$ & Le Maire et al. [13] \\
\hline $\begin{array}{c}\text { Normalized difference (ND } \\
{[710,925]}\end{array}$ & $\frac{\rho_{925}-\rho_{710}}{\rho_{925}+\rho_{710}}$ & Le Maire et al. [19] \\
\hline $\begin{array}{l}\text { Modified normalized difference } \\
\quad(\text { MND }[445,750])\end{array}$ & $\frac{\rho_{750}-\rho_{705}}{\rho_{750}+\rho_{705}-2 \rho_{445}}$ & $\begin{array}{c}\text { Sims and Gamon } \\
{[16]}\end{array}$ \\
\hline $\begin{array}{l}\text { Modified Chlorophyll absorption } \\
\text { ratio index (MCARI }[670,700] \text { ) }\end{array}$ & {$\left[\left(\rho_{700}-\rho_{670}\right)-0.2 \times\left(\rho_{700}-\rho_{550}\right)\right]\left(\frac{\rho_{700}}{\rho_{670}}\right)$} & Daughtry et al. [11] \\
\hline $\begin{array}{l}\text { Optimized soil-adjusted } \\
\text { vegetation index (OSAVI } \\
[670,800])\end{array}$ & $\frac{(1+0.16)\left(\rho_{800}-\rho_{670}\right)}{\rho_{800}+\rho_{670}+0.16}$ & Rondeaux et al. [47] \\
\hline MCARI/OSAVI $[705,750]$ & $\frac{\left[\left(\rho_{750}-\rho_{705}\right)-0.2 \times\left(\rho_{750}-\rho_{550}\right)\right]\left(\rho_{750} / \rho_{705}\right)}{(1+0.16)\left(\rho_{750}-\rho_{705}\right) /\left(\rho_{750}+\rho_{705}+0.16\right)}$ & Wu et al. [14] \\
\hline Red edge position (REP) & $-\left(c_{1}-c_{2}\right) /\left(m_{1}-m_{2}\right)$ & $\begin{array}{c}\text { Cho and Skidmore } \\
{[20]}\end{array}$ \\
\hline Red edge area $\left(\mathrm{S}_{\mathrm{RE}}\right)$ & $\sum_{\lambda=680}^{780} \rho_{\lambda}^{\prime}$ & Filella et al. [30] \\
\hline $\begin{array}{l}\text { Normalized area over reflectance } \\
\text { curve (NAOC }[643,795])\end{array}$ & $1-\frac{\int_{643}^{795} \rho_{\lambda} d \lambda}{\rho_{\max }(795-643)}$ & Delegido et al. [18] \\
\hline
\end{tabular}

\section{Results}

\subsection{Relationship between Foliar $\mathrm{Cu}$ and Chlorophyll Concentration}

The foliar $\mathrm{Cu}$ concentrations $(N=71)$ ranged from 6.58 to $107.71 \mathrm{mg} \cdot \mathrm{kg}^{-1}$ with a mean value of $41.36 \mathrm{mg} \cdot \mathrm{kg}^{-1}$, and the chlorophyll concentrations calculated by SPAD-502 chlorophyll readings ranged from 0.81 to $2.00 \mathrm{~g} \cdot \mathrm{kg}^{-1}$ with a mean value of $1.36 \mathrm{~g} \cdot \mathrm{kg}^{-1}$. Based on the concentrations of $\mathrm{Cu}$, the 71 samples could be classified into three groups: safe level $\left(0-30 \mathrm{mg} \cdot \mathrm{kg}^{-1}, N=40\right.$, mean $\left.=14.46 \mathrm{mg} \cdot \mathrm{kg}^{-1}\right)$, low pollution $\left(30-60 \mathrm{mg} \cdot \mathrm{kg}^{-1}, N=16\right.$, mean $\left.=53.30 \mathrm{mg} \cdot \mathrm{kg}^{-1}\right)$, and moderate pollution $\left(60-120 \mathrm{mg} \cdot \mathrm{kg}^{-1}, N=15\right.$, mean $\left.=100.33 \mathrm{mg} \cdot \mathrm{kg}^{-1}\right)$. The mean chlorophyll concentrations of the three groups were $1.51,1.32$ and $1.01 \mathrm{~g} \cdot \mathrm{kg}^{-1}$, respectively. Figure 4 shows that the $\mathrm{Cu}$ concentration was negatively and strongly correlated with the chlorophyll concentration $(r=-0.719, p<0.001)$. 


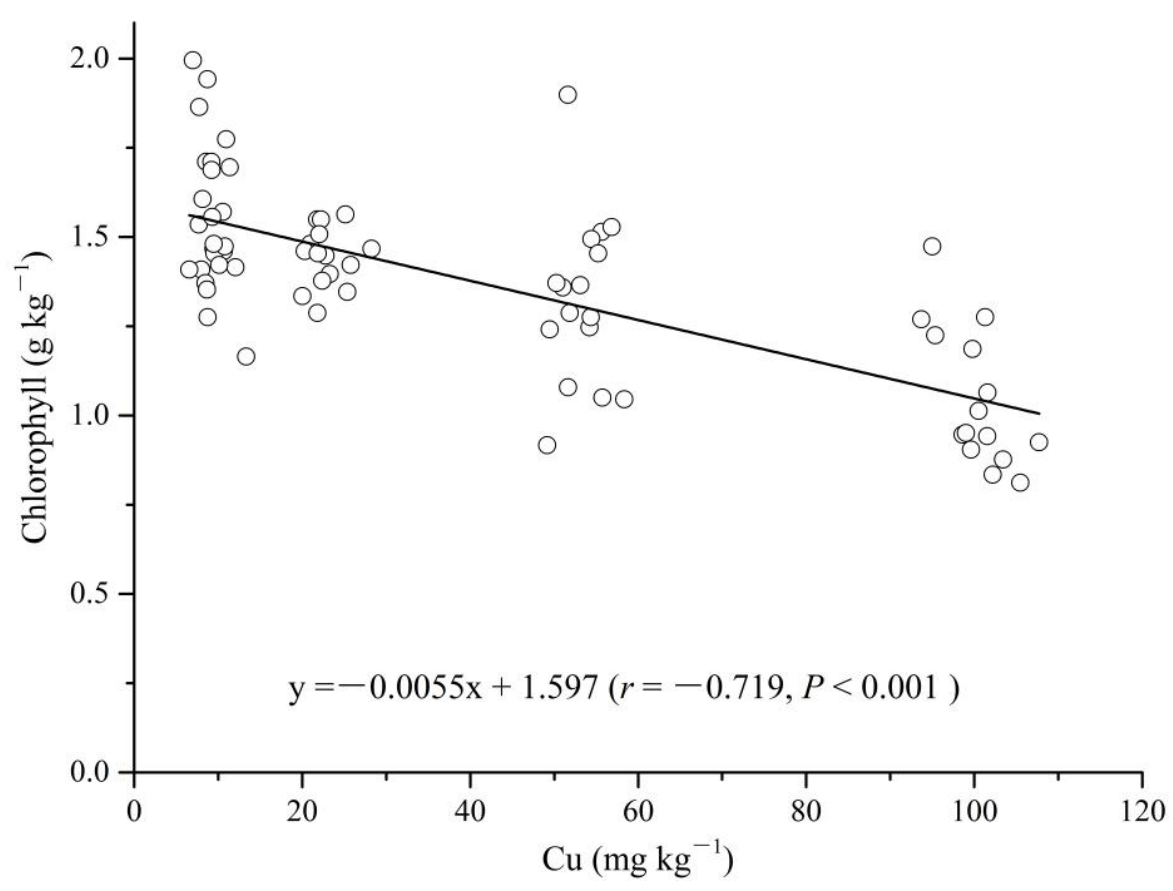

Figure 4. Relationship between foliar $\mathrm{Cu}$ and chlorophyll concentration $(N=71)$.

\subsection{Extraction of the Wavelet-Based Area Parameter from Canopy Reflectance Spectra}

Figure 5 illustrates the reconstructed approximation and detail reflectance (400-1350 nm) with eight different decomposition levels using the DWT method. Evidently, the derivative reflectance (Figure 5b) strengthened the spectral differences of original reflectance (Figure 5a). The reconstructed approximation reflectance preserved the spectral features (e.g., around $600 \mathrm{~nm}$ ) of derivative reflectance from the first to fourth decomposition level (Figure $5 \mathrm{c}-\mathrm{f}$ ); and the reconstructed detail reflectance magnified the subtle features (e.g., around $700 \mathrm{~nm}$ ) at the third and fourth decomposition level (e.g., Figure 5m,n).

The higher decomposition level resulted in the coarser spectral resolution and the greater loss of spectral information (e.g., Figure 5i,j), while the lower decomposition level might have more noise for reconstructed detail reflectance (e.g., Figure 5k,1).

The order of Minkowski distance $\left(D_{\text {Mink }}\right)$ was a1 $<$ a $<$ a3 $<$ a $4<$ a $<$ a $6<$ a $<$ a8 (Figure 6a), suggesting that the reconstructed approximation reflectance at the first to fourth decomposition level were more similar to derivative reflectance than those at the fifth to eighth decomposition level. The reconstructed detail reflectance at the fourth decomposition level (d4) showed the most pronounced relationship with foliar $\mathrm{Cu}$ concentration (Figure 6b) among the eight decomposition levels.

Given the above results, the optimal decomposition level was chosen at the fourth level, because this level met the two proposed rules described in Section 3.3. The d4 reflectance was then used for further area parameter extraction to magnify the subtle spectral information sensitive to $\mathrm{Cu}$ variation. 

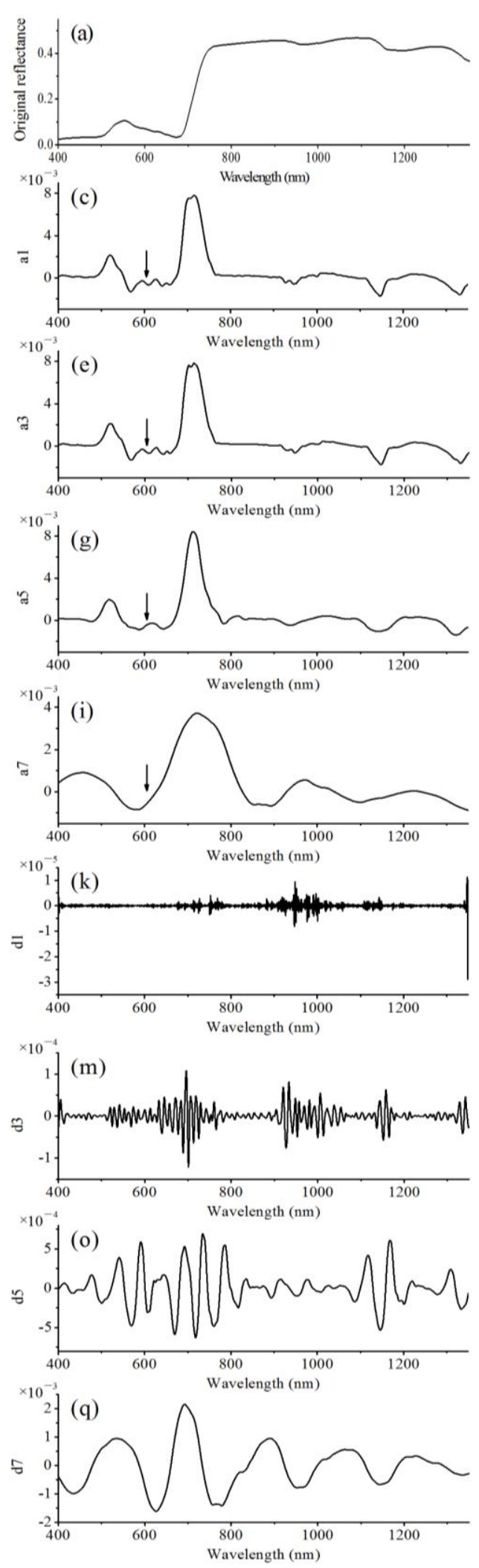
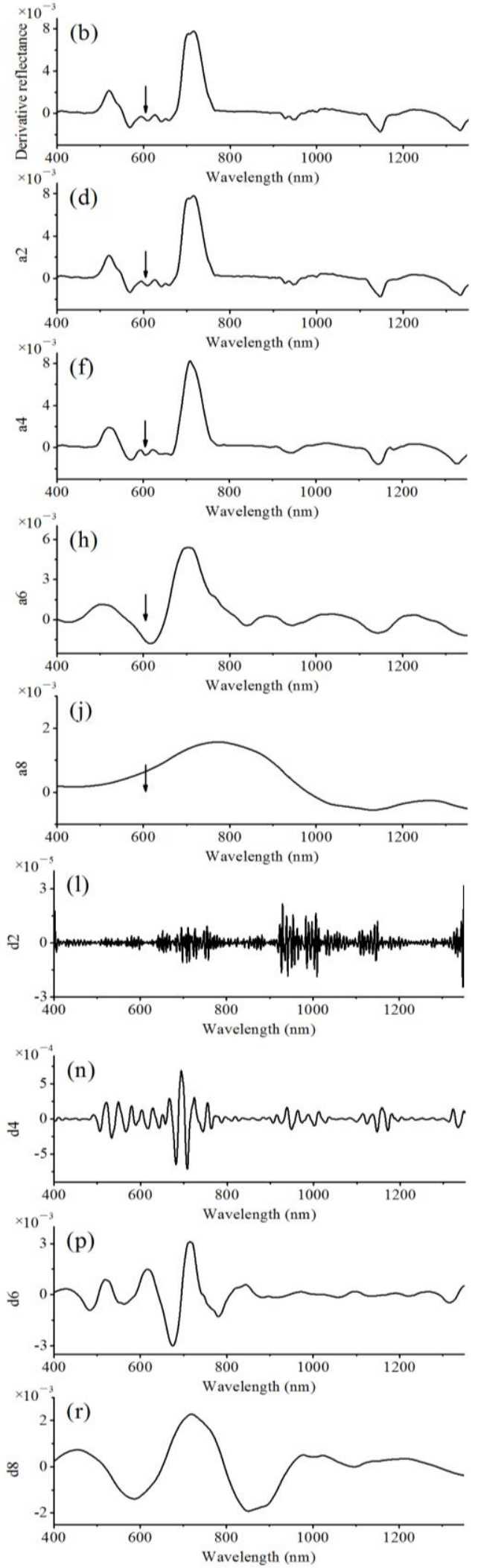

Figure 5. One example (Sample 1) of plots of original reflectance (a), derivative reflectance (b), reconstructed approximation reflectance at the first to eighth decomposition level $(\mathbf{c}-\mathbf{j})$ and reconstructed detail reflectance at the first to eighth decomposition level $(\mathbf{k}-\mathbf{r})$ using discrete wavelet transform (db5 was the mother wavelet function). 

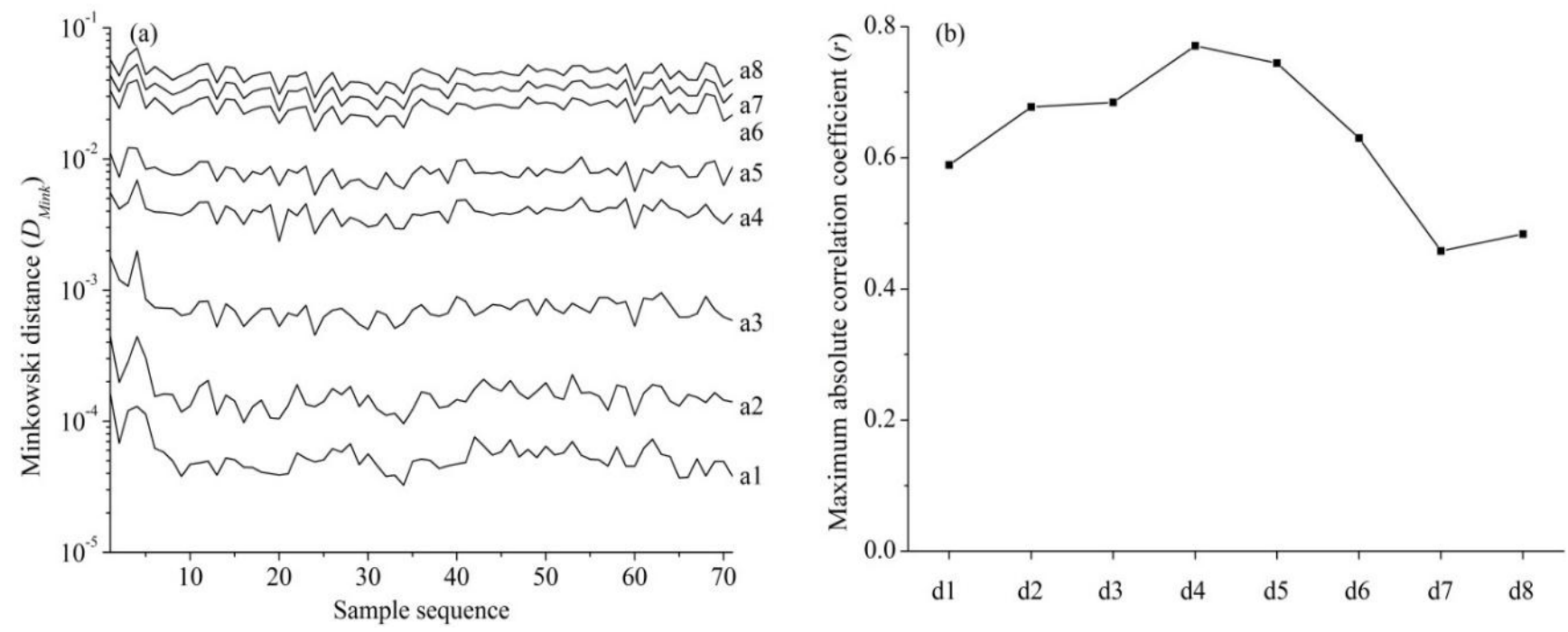

Figure 6. (a) The Minkowski distance between derivative reflectance and reconstructed approximation reflectance (a1, a2, a3, a4, a5, a6, a7 and a8) at different decomposition levels for each sample $(N=71)$ and $(\mathbf{b})$ the maximum absolute Pearson's correlation coefficient $(r)$ between foliar $\mathrm{Cu}$ concentration and reconstructed detail reflectance $(\mathrm{d} 1, \mathrm{~d} 2$, d3, d4, d5, d6, d7 and d8) at different decomposition levels.

Figure 7a,b demonstrated that the samples with the higher $\mathrm{Cu}$ concentrations tended to have stronger $\mathrm{d} 4$ reflectance over $605-715 \mathrm{~nm}$, while the $\mathrm{d} 4$ reflectance over the other continuous spectral regions did not exhibit such close relationship with $\mathrm{Cu}$ concentration. In contrast, the mean original (Figure 7c) and first derivative reflectance spectra (Figure 7d) over 605-715 nm did not have evident peaks and valleys that existed for $\mathrm{d} 4$ reflectance spectra to enhance the potential subtle spectral features, and their reflectance values did not show a good relationship with $\mathrm{Cu}$ concentrations because their reflectance values in the low pollution group and safe level group were similar and hardly distinguished.

Table 2. Pearson's correlation coefficient $(r)$ between foliar $\mathrm{Cu}$ concentrations and $\mathrm{S}_{\mathrm{WT}}(\lambda 1-\lambda 2)$ with different spectral regions.

\begin{tabular}{cccccc}
\hline $\boldsymbol{\lambda 1} \mathbf{( n m})$ & $\boldsymbol{\lambda} \mathbf{2}(\mathbf{n m})$ & $\boldsymbol{r}$ & $\boldsymbol{\lambda 1} \mathbf{( n m})$ & $\boldsymbol{\lambda 2} \mathbf{( n m )}$ & $\boldsymbol{r}$ \\
\hline \multirow{6}{*}{605} & 715 & 0.836 & 605 & & 0.836 \\
& 720 & 0.838 & 600 & & 0.832 \\
& 725 & 0.835 & 595 & & 0.816 \\
& 730 & 0.832 & 590 & & 0.805 \\
& 735 & 0.831 & 585 & & 0.794 \\
& 740 & 0.827 & 580 & 715 & 0.782 \\
& 745 & 0.815 & 575 & & 0.779 \\
& 750 & 0.807 & 570 & & 0.758 \\
& 755 & 0.791 & 565 & & 0.723 \\
& 760 & 0.778 & 560 & & 0.720 \\
& 765 & 0.762 & 555 & & 0.718 \\
\hline
\end{tabular}


To determine the precise spectral region, the rough spectral region $(605-715 \mathrm{~nm})$ was slightly tuned with different adjacent spectral regions, and the Pearson's correlation coefficients $(r)$ between the corresponding area parameters and $\mathrm{Cu}$ concentrations $(N=71)$ were calculated, respectively (Table 2). Results showed that the spectral region over 605-720 $\mathrm{nm}$ was optimal, because $\mathrm{S}_{\mathrm{WT}}(605-720)$ had the strongest correlation $(r=0.838, p<0.001)$ with $\mathrm{Cu}$ concentration. The area parameter $\mathrm{S}_{\mathrm{WT}}(605-720)($ range $=0.0113-0.0341$, mean $=0.0233, N=71)$ was then used for further analysis.
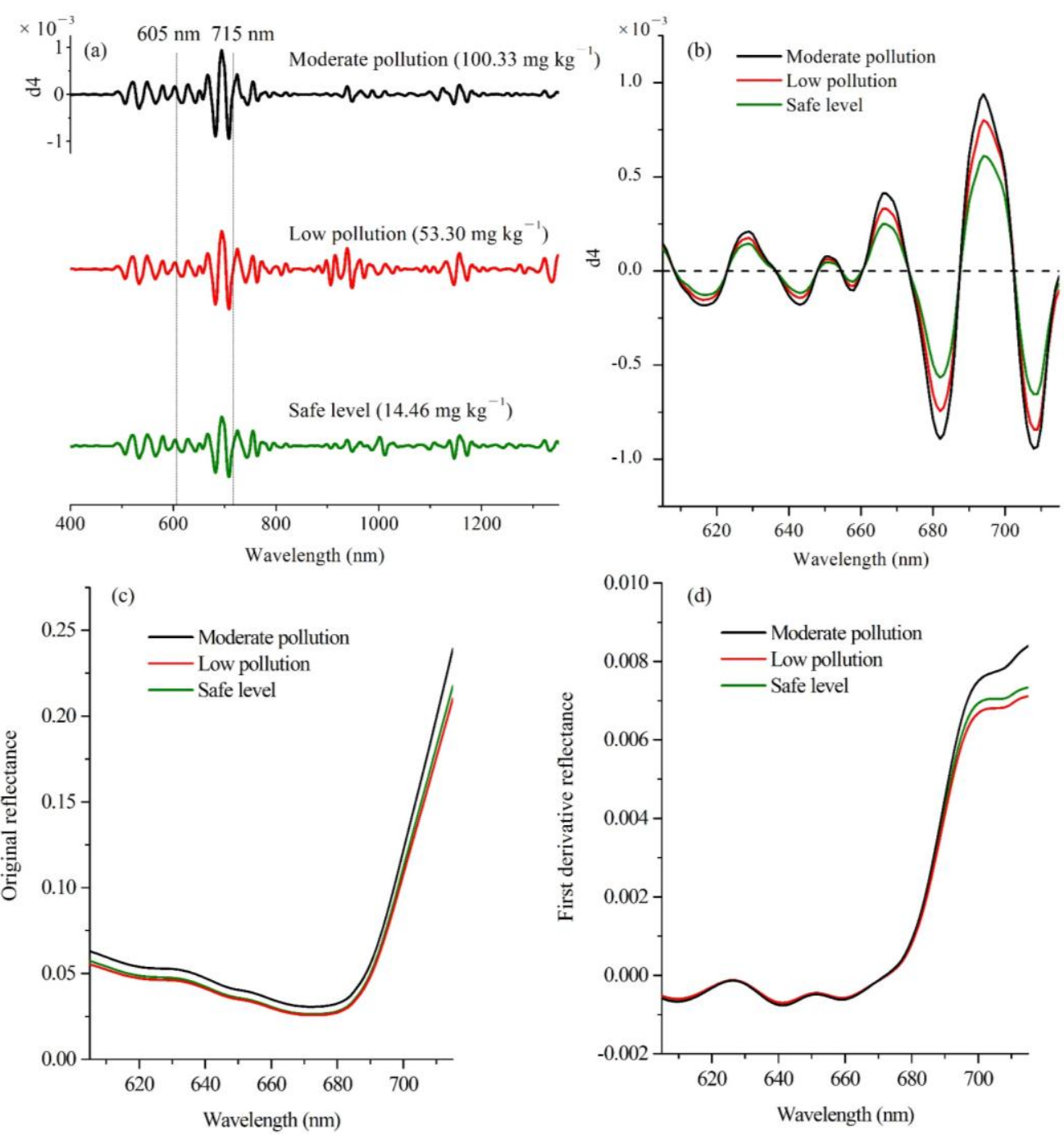

Figure 7. (a) The mean $\mathrm{d} 4$ reflectance $(400-1350 \mathrm{~nm})$, (b) the amplifying $\mathrm{d} 4 \mathrm{reflectance}$ $(605-715 \mathrm{~nm}),(\mathbf{c})$ the mean original reflectance $(605-715 \mathrm{~nm}),(\mathbf{d})$ the mean first derivative reflectance $(605-715 \mathrm{~nm})$ for the samples in the group of safe level $\left(0-30 \mathrm{mg} \cdot \mathrm{kg}^{-1}\right)$, low pollution $\left(30-60 \mathrm{mg} \cdot \mathrm{kg}^{-1}\right)$, and moderate pollution $\left(60-120 \mathrm{mg} \cdot \mathrm{kg}^{-1}\right)$, respectively.

\subsection{Foliar Cu Estimation with the Wavelet-Based Area Parameter}

A total of 1000 linear calibration models were established with 1000 calibration sets $(N=36)$ for estimating foliar $\mathrm{Cu}$ concentrations with the wavelet-based area parameter ( $\mathrm{S}_{\mathrm{WT}}$ (605-720)), and they were independently validated with the corresponding validation sets $(N=35)$ (Table 3$)$. Evidently, the 
calibration and validation results varied greatly with different dataset partitioning experiments. The general model using the mean $k$ and $b$ values $\left(Y_{C u}=7098.05 \times S_{W T(605-720)}-129.12\right)$ could reflect the general and unbiased relationship between $\mathrm{Cu}$ concentration and $\mathrm{SWT}_{\mathrm{WT}}(605-720)$. The 1000 calibration models reported a mean $\mathrm{R}^{2}$ val value of 0.710 and $\mathrm{RPD}$ value of 1.75 .

Table 3. Calibration and validation results of estimating foliar $\mathrm{Cu}$ concentration based on 1000 random dataset partitioning experiments.

\begin{tabular}{|c|c|c|c|c|c|c|c|}
\hline \multirow[b]{2}{*}{ Statistics } & \multicolumn{2}{|c|}{$Y_{C u}=k S_{W T(605-720)}+b$} & \multicolumn{2}{|c|}{ Calibration $(N=36)$} & \multicolumn{3}{|c|}{ Validation $(N=35)$} \\
\hline & $\boldsymbol{k}$ & $b$ & $\begin{array}{l}\mathrm{RMSE}_{\mathrm{Cal}} \\
\left(\mathrm{mg} \cdot \mathrm{kg}^{-1}\right)\end{array}$ & $\mathbf{R}^{2}$ Cal & $\begin{array}{l}\text { RMSE }_{\text {Val }} \\
\left(\mathrm{mg} \mathrm{kg}^{-1}\right)\end{array}$ & $\mathbf{R}^{2}$ Val & RPD \\
\hline Minimum & 5176.71 & -193.28 & 11.82 & $0.491^{* *}$ & 14.49 & $0.516^{* *}$ & 1.16 \\
\hline Maximum & 9800.62 & -89.55 & 22.67 & $0.885^{* *}$ & 26.91 & $0.822^{* *}$ & 2.24 \\
\hline Mean & 7098.05 & -129.12 & 18.37 & $0.710^{* *}$ & 20.16 & $0.706^{* *}$ & 1.75 \\
\hline
\end{tabular}

** $p<0.001$. $\mathrm{RMSE}_{\mathrm{Cal}}$ and $\mathrm{RMSE}_{\mathrm{Val}}$ represent root mean square error of calibration and validation, respectively. $\mathrm{R}^{2} \mathrm{Cal}$ and $\mathrm{R}^{2}$ Val represent determination coefficient of calibration and validation, respectively. RPD represents residual prediction deviation.

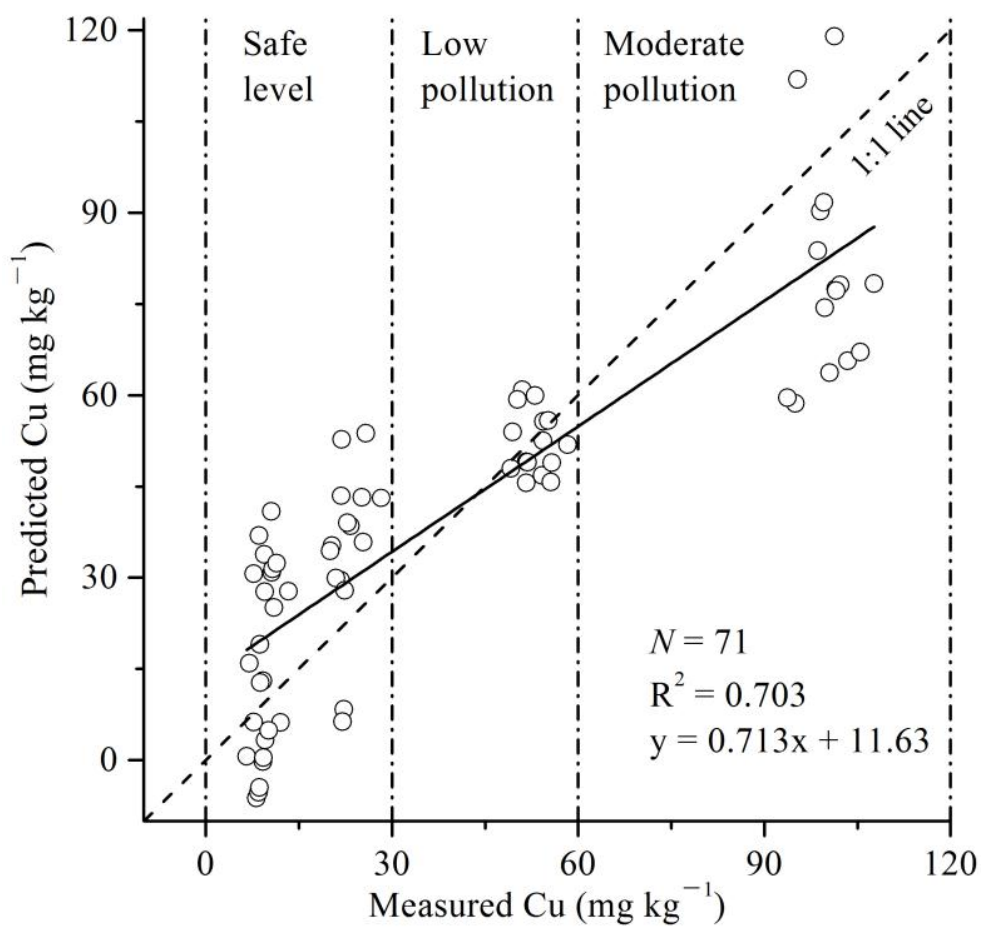

Figure 8. Scatterplot of the measured against predicted $\mathrm{Cu}$ concentration with the full dataset $(N=71)$ based on the general model $\left(Y_{C u}=7098.05 \times S_{W T(605-720)}-129.12\right)$ for $\mathrm{Cu}$ estimation.

The scatterplot illustrates the agreement between the measured and predicted $\mathrm{Cu}$ concentrations using the general model $(N=71)$ (Figure 8). The sample points in the low pollution group (30-60 mg $\left.\mathrm{kg}^{-1}\right)$ were closer to 1:1 line than the other two groups. The mean absolute relative error (MARE) between predicted and measured values was $63.07 \%, 9.82 \%$ and $34.86 \%$ for the safe level, low pollution, and moderate pollution groups, respectively. This indicates that more reliable and 
accurate prediction of foliar $\mathrm{Cu}$ concentrations can be performed at the concentration range of $30-60 \mathrm{mg} \cdot \mathrm{kg}^{-1}$.

\subsection{Performance Comparison between the Wavelet-Based Area Parameter and Published Spectral Parameters}

The performance of the wavelet-based area parameter ( $\mathrm{S}_{\mathrm{WT}}(605-720)$ ) was compared to that of ten classical chlorophyll-related spectral parameters and one published wavelet-based spectral parameter (FDWT $480-850)$ for quantifying foliar $\mathrm{Cu}$ concentration $(N=71)$ (Table 4). The bootstrapping results showed that $\mathrm{S}_{\mathrm{WT}}$ (605-720) provided the highest mean determination coefficient for quantifying $\mathrm{Cu}$ concentration $\left(\mathrm{R}^{2}=0.706, p<0.001\right)$ among these parameters. The ANOVA test results showed there to be significant difference $(p<0.05)$ between $S_{W T}$ (605-715) and each of the 11 published spectral parameters in the mean $\mathrm{R}^{2}$ values for foliar $\mathrm{Cu}$ quantification.

Table 4. Bootstrapped determination coefficient $\left(\mathrm{R}^{2}\right)$ for quantifying foliar $\mathrm{Cu}$ concentration with the 10 classical chlorophyll-related spectral parameters listed in Table 1 and one published wavelet-based area parameter using the full dataset $(N=71)$.

\begin{tabular}{cccc}
\hline Spectral Parameter & Mean & LCL 95\% & UCL 95\% \\
\hline MSR [670, 800] & 0.087 & 0.001 & 0.218 \\
MSR [500, 720] & $0.192^{* *}$ & 0.040 & 0.315 \\
ND [710, 925] & $0.193^{* *}$ & 0.058 & 0.336 \\
MND [445, 750] & $0.187^{* *}$ & 0.055 & 0.312 \\
MCARI [670, 700] & $0.515^{* *}$ & 0.394 & 0.614 \\
OSAVI [670, 800] & $0.168^{* *}$ & 0.021 & 0.327 \\
MCARI/OSAVI [705, 750] & 0.039 & 0.010 & 0.157 \\
REP & $0.178^{* *}$ & 0.038 & 0.305 \\
SRE $_{\text {RE }}$ & $0.214^{* *}$ & 0.046 & 0.393 \\
NAOC [643, 795] & $0.136^{*}$ & 0.027 & 0.262 \\
FDWT $480-850$ & $0.145^{*}$ & 0.107 & 0.276 \\
S $_{\text {WT (605-720) }}$ (this paper) & $0.706^{* *}$ & 0.570 & 0.773 \\
\hline
\end{tabular}

${ }^{*} p<0.01,{ }^{* *} p<0.001$. LCL and UCL represent lower and upper confidence limits, respectively.

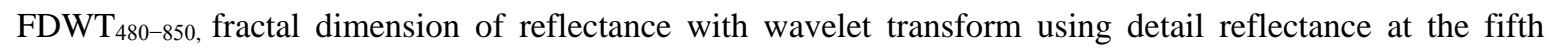
decomposition level in the spectral region of $480-850 \mathrm{~nm}$.

Despite SRE, NAOC [643, 795], and SWT (605-720) are area parameters with the same spectral region (680-720 nm), $S_{R E}$ and NAOC [643, 795] showed much poorer correlations with foliar $\mathrm{Cu}$ concentrations than $S_{W T}$ (605-720). This indicates that the spectral information over $605-720 \mathrm{~nm}$ was more sensitive to $\mathrm{Cu}$ variations than that over the red edge region $(680-780 \mathrm{~nm})$ and $643-795 \mathrm{~nm}$. Both of FDWT $480-850$ and $\mathrm{SWT}_{\text {(605-720) }}$ are wavelet-based spectral parameters, but FDWT480-850 exhibited much poorer performance than $\mathrm{S}_{\mathrm{WT}}(605-720)$.

Among the 10 classical chlorophyll-related spectral parameters, MCARI [670, 700] had the closest correlation with $\mathrm{Cu}$ concentration $\left(\mathrm{R}^{2}=0.515, p<0.001\right)$, while the other nine parameters showed much poorer correlations, indicating that these parameters were not sensitive enough to effectively extract $\mathrm{Cu}$ concentration information. In addition, the mean red edge position (REP) for safe level 
$\left(0-30 \mathrm{mg} \cdot \mathrm{kg}^{-1}\right)$, low pollution $\left(30-60 \mathrm{mg} \cdot \mathrm{kg}^{-1}\right)$, and moderate pollution groups $\left(60-120 \mathrm{mg} \cdot \mathrm{kg}^{-1}\right)$ of $\mathrm{Cu}$ concentrations was $709.78,707.65$ and $707.53 \mathrm{~nm}$, respectively. This suggests that the REP tends to move to the shorter wavelengths as the concentration of $\mathrm{Cu}$ increases.

\section{Discussion}

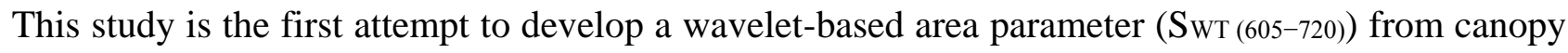
reflectance to enhance the subtle spectral changes related to foliar chlorophyll concentration under $\mathrm{Cu}$ stress, and use it to indirectly estimate $\mathrm{Cu}$ concentration in Carex leaves. According to the interpretation of $\mathrm{R}^{2}$ value given by Williams [48] and RPD value given by Saeys et al. [49], the general model $\left(Y_{C u}=7098.05 \times S_{W T(605-720)}-129.12\right)$ using the mean $k$ and $b$ values of the 1000 models (Table 3) demonstrated capable of distinguishing between high and low values of foliar $\mathrm{Cu}$ concentrations $\left(0.66<\mathrm{R}^{2} \mathrm{Val}<0.81,1.5<\mathrm{RPD}<2.0\right)$. The main mechanism of such successful estimation originates from the strong correlation between $\mathrm{Cu}$ and chlorophyll (Figure 4). Despite the element of $\mathrm{Cu}$ in plant leaves does not have evident absorption features, the high $\mathrm{Cu}$ concentration might trigger the decrease of foliar chlorophyll concentration, which can change the leaf reflectance spectrum $[4,23,25,29]$. This can be interpreted by that: the high concentration of $\mathrm{Cu}$ can stimulate the formation of free radicals and reduce the number of pores among mesophyll cells [1,3]; and chlorophyll concentration is a main influencing factor on leaf and canopy spectral characteristics in the visible region [16,47]. Hence, our study employed the coupling of wavelet transform and area parameters to capture the potential spectral changes related to chlorophyll under $\mathrm{Cu}$ stress for the accurate estimation of foliar $\mathrm{Cu}$ concentration. To some extent, the spectral region of 605-720 nm was the sensitive region reflecting such subtle spectral changes. The region of $605-680 \mathrm{~nm}$ is the strong absorption region of chlorophyll [8,11], and the region of $680-720 \mathrm{~nm}$ is part of the red edge region (680-720 nm), which has been found to be closely related to foliar chlorophyll concentration [12,16,23,24].

The general model involved more accurate predictions at the low pollution level than that at the safe level for the estimation of $\mathrm{Cu}$ concentrations (Figure 8), indicating that $\mathrm{SWT}_{\mathrm{WT}}(605-720)$ had the potential to detect low levels of $\mathrm{Cu}$ pollution in Carex leaves. Several studies have attempted to use shifts in the REP to detect heavy metal pollution in plant leaves, because REP is sensitive to metal-polluted leaves [23]. The current study and a previous report of Liu et al. [22] both showed there to be a blue shift in the REP as concentrations of $\mathrm{Cu}$ increased in plant leaves. However, both studies reported a very low relationship between REP and foliar $\mathrm{Cu}$ concentrations. This might be because the $\mathrm{Cu}$ concentrations in plant leaves were not high enough to significantly affect the reflectance amplitude in the near-infrared waveband.

Published studies have reported $\mathrm{R}^{2}$ val values of $0.740-0.967$ for foliar $\mathrm{Cu}$ estimation with hyperspectral remote sensing techniques [21-23]. The current study obtained $\mathrm{R}^{2}$ val values of 0.516-0.822 with a mean value of 0.706 for foliar $\mathrm{Cu}$ estimation (Table 3) based on 1000 random dataset partitioning experiments. The relatively low prediction results for $\mathrm{Cu}$ estimation in this study might be due to the narrow range of $\mathrm{Cu}$ concentrations $\left(6.58-107.71 \mathrm{mg} \cdot \mathrm{kg}^{-1}\right)$ within the leaf samples collected in natural wetlands, compared with that in other studies. For example, Liu et al. [21] provided $\mathrm{Cu}$ concentrations with $60-576 \mathrm{mg} \cdot \mathrm{kg}^{-1}$ within leaf samples collected along a Cu-polluted 
river. An unrelated Liu et al. [23] reported $\mathrm{Cu}$ concentrations with $18.12-502.05 \mathrm{mg} \cdot \mathrm{kg}^{-1}$ within leaf samples cultivated in the laboratory using soils with artificially-controlled $\mathrm{Cu}$ concentrations.

The bootstrapping (Table 4) and ANOVA test results demonstrated the statistically significant superiority of SWT (605-720) over the classical chlorophyll-related and published wavelet-based spectral parameters for estimating $\mathrm{Cu}$ concentration in Carex leaves. One possible reason for this may be that the chlorophyll-related spectral parameters were directly correlated with foliar chlorophyll content and were indirectly related to $\mathrm{Cu}$ concentrations, which rendered the correlations less closely. Secondly, the published spectral parameters and wavelet coefficients may be sensitive to background effects, plant species, study areas, or vegetative stages, possibly rendering predictions of biochemical or biophysical parameters of plants inconsistent and causing these spectral parameters not generalized in different environment conditions [12,14,16,22,47]. Noticeably, MCARI [670, 700] behaved much better than the other nine chlorophyll-related spectral parameters. It is hard to interpret this outperformance; the main reason may be that both of 670 and $700 \mathrm{~nm}$ might be sensitive to chlorophyll variation as well as to $\mathrm{Cu}$ variation in plant leaves.

The estimation results further demonstrate the successful application of WT in heavy metal estimation in plant leaves, because WT could preserve the general spectral features and location, as well as magnify subtle spectral changes (Figure 5). Many studies also have made good use of this advantage in different fields of remote sensing, and they obtained good accuracies of classification or estimation $[9,22,38,39]$. However, the evident disadvantage of WT is that there is still no single universal methodology for choosing the optimal mother wavelet function and decomposition level of signal [45]. For this reason, such selection is normally determined by complicated optimization calculation or prior knowledge. For example, Koger et al. [38] investigated 36 different mother wavelets to determine the effect of mother wavelet selection on the ability to detect the presence of pitted morning-glory, demonstrating that Daubechies wavelet ( $\mathrm{db} 3$ and $\mathrm{db} 5$ ) and Coiflets wavelet (coif5) were the best mother wavelets; Pu and Gong [39] and Liu et al. [22] directly chose db3 at the eighth decomposition level and $\mathrm{db} 5$ at the fifth decomposition level based on prior knowledge, respectively. In contrast, the present study combined prior knowledge with simple optimization calculation (i.e., spectral similarity analysis and correlation analysis) in choosing the optimum mother wavelet function and decomposition level to avoid time-consuming experiments and obtain reliable results.

In this study, the optimum decomposition level for WT analysis of canopy hyperspectral data was four (or scale $\left.2^{4}=16\right)$, suggesting that the original signal $(400-1350 \mathrm{~nm}$ ) was decomposed into several wavelet coefficients with a spectral interval of $16 \mathrm{~nm}$. Among the hyperspectral sensors used frequently, HyMap offers a similar bandwidth (15-16 nm) in the visible and near-infrared waveband (450-890 nm). It may be helpful to extend the wavelet-based area parameter SwT (605-720) from canopy reflectance to HyMap image reflectance, which may make it possible to monitor $\mathrm{Cu}$ concentrations in Carex leaves at the landscape scale and improve the early warning of $\mathrm{Cu}$ pollution in Carex-dominated wetland ecosystem.

Admittedly, the applicability of the proposed wavelet-based area parameter for foliar $\mathrm{Cu}$ estimation to the other situations might be limited due to the differences of species, vegetative stages, and biological and environmental conditions, which is a tough issue for statistical modeling methods in retrieving biochemical or biophysical parameters of plants. However, the method presented in this pilot study may be used to estimate the concentrations of other heavy metals. Further, the remotely-sensed 
estimation of heavy metal concentrations at the canopy or landscape level is still promising for decision-makers and farmers to rapidly understand the growth and metal-pollution condition of plants without intense sampling and chemical analyses.

\section{Conclusions}

In order to enhance the subtle spectral changes related to foliar chlorophyll concentration under $\mathrm{Cu}$ stress, this study attempted to develop a wavelet-based area parameter ( $\mathrm{S}_{\mathrm{WT}}$ (605-720) ) from canopy hyperspectral reflectance to estimate $\mathrm{Cu}$ concentration in Carex leaves. The main conclusions that can be drawn from the present study are:

(1) The wavelet-based area parameter could be used to indirectly estimate foliar $\mathrm{Cu}$ concentration through the strong correlation between $\mathrm{Cu}$ and chlorophyll;

(2) The wavelet-based area parameter has the potential ability of detecting low concentrations of $\mathrm{Cu}$ pollution in Carex leaves;

(3) The wavelet-based area parameter was superior to published chlorophyll-related and wavelet-based spectral parameters for estimating $\mathrm{Cu}$ concentration in Carex leaves.

Despite the abovementioned advantages of the wavelet-based area parameter technique, further research is needed to test its transferability and robustness for estimating $\mathrm{Cu}$ concentrations on other plant species in different biological and environmental conditions.

\section{Acknowledgments}

This study was supported by the National Natural Science Foundation of China (Grant No. 41171290). The authors would like to thank all the anonymous reviewers and the associate editor for their constructive comments and suggestions on this manuscript.

\section{Author Contributions}

Junjie Wang analyzed the data, reviewed the literature and prepared the manuscript. Tiezhu Shi took part in the fieldwork. Guofeng Wu, Tiejun Wang and Andrew K. Skidmore developed the research plan. All authors contributed equally to the editing of the manuscript.

\section{Conflicts of Interest}

The authors declare no conflict of interest.

\section{References}

1. Hall, J. Cellular mechanisms for heavy metal detoxification and tolerance. J. Exp. Bot. 2002, 53, 1-11.

2. Dietz, K.J.; Baier, M.; Krämer, U. Free radicals and reactive oxygen species as mediators of heavy metal toxicity in plants. In Heavy Metal Stress in Plants; Prasad, M.N.V., Hagemeyer, J., Eds.; Springer: Berlin, Germany, 1999; pp. 73-97.

3. Krause, G.H.; Kaiser, H. Plant response to heavy metals and sulphur dioxide. Environ. Pollut. 1977, 12, 63-71. 
4. Macinnis-Ng, C.M.; Ralph, P.J. Towards a more ecologically relevant assessment of the impact of heavy metals on the photosynthesis of the seagrass, Zostera capricorni. Mar. Pollut. Bull. 2002, 45, 100-106.

5. Markert, B. Plants as Biomonitors: Indicators for Heavy Metals in the Terrestrial Environment; VCH Publishers Ltd.: Cambridge, UK, 1993.

6. Kooistra, L.; Salas, E.; Clevers, J.; Wehrens, R.; Leuven, R.; Nienhuis, P.; Buydens, L. Exploring field vegetation reflectance as an indicator of soil contamination in river floodplains. Environ. Pollut. 2004, 127, 281-290.

7. Schlerf, M.; Atzberger, C.; Hill, J. Remote sensing of forest biophysical variables using HyMap imaging spectrometer data. Remote Sens. Environ. 2005, 95, 177-194.

8. Curran, P.J.; Dungan, J.L.; Peterson, D.L. Estimating the foliar biochemical concentration of leaves with reflectance spectrometry: Testing the Kokaly and Clark methodologies. Remote Sens. Environ. 2001, 76, 349-359.

9. Blackburn, G.A.; Ferwerda, J.G. Retrieval of chlorophyll concentration from leaf reflectance spectra using wavelet analysis. Remote Sens. Environ. 2008, 112, 1614-1632.

10. Abdel-Rahman, E.M.; Ahmed, F.B.; van den Berg, M. Estimation of sugarcane leaf nitrogen concentration using in situ spectroscopy. Int. J. Appl. Earth Obs. Geoinf. 2010, 12, S52-S57.

11. Daughtry, C.; Walthall, C.; Kim, M.; De Colstoun, E.B.; McMurtrey, J., III. Estimating corn leaf chlorophyll concentration from leaf and canopy reflectance. Remote Sens. Environ. 2000, 74, 229-239.

12. Gitelson, A.A.; Keydan, G.P.; Merzlyak, M.N. Three-band model for noninvasive estimation of chlorophyll, carotenoids, and anthocyanin contents in higher plant leaves. Geophys. Res. Lett. 2006, 33, L11402.

13. Le Maire, G.; Francois, C.; Dufrene, E. Towards universal broad leaf chlorophyll indices using PROSPECT simulated database and hyperspectral reflectance measurements. Remote Sens. Environ. 2004, 89, 1-28.

14. Wu, C.; Niu, Z.; Tang, Q.; Huang, W. Estimating chlorophyll content from hyperspectral vegetation indices: Modeling and validation. Agric. For. Meteorol. 2008, 148, 1230-1241.

15. Cheng, T.; Rivard, B.; Sanchez-Azofeifa, A. Spectroscopic determination of leaf water content using continuous wavelet analysis. Remote Sens. Environ. 2011, 115, 659-670.

16. Sims, D.A.; Gamon, J.A. Relationships between leaf pigment content and spectral reflectance across a wide range of species, leaf structures and developmental stages. Remote Sens. Environ. 2002, 81, 337-354.

17. Chen, J.M. Evaluation of vegetation indices and a modified simple ratio for boreal applications. Can. J. Remote Sens. 1996, 22, 229-242.

18. Delegido, J.; Alonso, L.; González, G.; Moreno, J. Estimating chlorophyll content of crops from hyperspectral data using a normalized area over reflectance curve (NAOC). Int. J. Appl. Earth Obs. Geoinf. 2010, 12, 165-174.

19. Le Maire, G.; François, C.; Soudani, K.; Berveiller, D.; Pontailler, J.-Y.; Bréda, N.; Genet, H.; Davi, H.; Dufrêne, E. Calibration and validation of hyperspectral indices for the estimation of broadleaved forest leaf chlorophyll content, leaf mass per area, leaf area index and leaf canopy biomass. Remote Sens. Environ. 2008, 112, 3846-3864. 
20. Cho, M.A.; Skidmore, A.K. A new technique for extracting the red edge position from hyperspectral data: The linear extrapolation method. Remote Sens. Environ. 2006, 101, 181-193.

21. Liu, Y.; Chen, H.; Wu, G.; Wu, X. Feasibility of estimating heavy metal concentrations in Phragmites australis using laboratory-based hyperspectral data-A case study along Le'an River, China. Int. J. Appl. Earth Obs. Geoinf. 2010, 12, S166-S170.

22. Liu, M.; Liu, X.; Ding, W.; Wu, L. Monitoring stress levels on rice with heavy metal pollution from hyperspectral reflectance data using wavelet-fractal analysis. Int. J. Appl. Earth Obs. Geoinf. 2011, 13, 246-255.

23. Liu, S.; Liu, X.; Hou, J.; Chi, G.; Cui, B. Study on the spectral response of Brassica campestris L. leaf to the copper pollution. Sci. China Ser. E-Tech. Sci. 2008, 51, 202-208.

24. Ren, H.-Y.; Zhuang, D.-F.; Pan, J.-J.; Shi, X.-Z.; Wang, H.-J. Hyper-spectral remote sensing to monitor vegetation stress. J. Soil Sediment 2008, 8, 323-326.

25. Milton, N.; Ager, C.; Eiswerth, B.; Power, M. Arsenic-and selenium-induced changes in spectral reflectance and morphology of soybean plants. Remote Sens. Environ. 1989, 30, 263-269.

26. Kabata-Pendias, A.; Pendias, H. Trace Element in Soil and Plants; CRC Press: Boca Raton, FL, USA, 1984.

27. Wessman, C.A. Estimating canopy biochemistry through imaging spectrometry. In Imaging Spectrometry-A Tool for Environmental Observations; Hill, J., Megier, J., Eds.; Kluwer Academic Publishers: Dordrecht, The Netherlands, 1994; pp. 57-69.

28. Nagajyoti, P.; Lee, K.; Sreekanth, T. Heavy metals, occurrence and toxicity for plants: A review. Environ. Chem. Lett. 2010, 8, 199-216.

29. Chi, G.; Chen, X.; Shi, Y.; Liu, X. Spectral response of rice (Oryza sativa L.) leaves to $\mathrm{Fe}^{2+}$ stress. Sci. China Ser. C-Life Sci. 2009, 52, 747-753.

30. Filella, I.; Serrano, L.; Serra, J.; Penuelas, J. Evaluating wheat nitrogen status with canopy reflectance indices and discriminant analysis. Crop Sci. 1995, 35, 1400-1405.

31. Liu, M.; Liu, X.; Li, T.; Xiu, L. Analysis of hyperspectral singularity of rice under Zn pollution stress. Trans. CSAE 2010, 26, 191-197. (In Chinese)

32. Kaewpijit, S.; Le Moigne, J.; El-Ghazawi, T. Automatic reduction of hyperspectral imagery using wavelet spectral analysis. IEEE Trans. Geosci. Remote Sens. 2003, 41, 863-871.

33. Misiti, M.; Misiti, Y.; Oppenheim, G.; Poggi, J.-M. Matlab Wavelet Toolbox User's Guide Version 3; The MathWorks, Inc.: Natick, MA, USA, 2004.

34. Graps, A. An introduction to wavelets. IEEE Comput. Sci. Eng. 1995, 2, 50-61.

35. Schmidt, K.; Skidmore, A. Smoothing vegetation spectra with wavelets. Int. J. Remote Sens. 2004, 25, 1167-1184.

36. Bruce, L.M.; Koger, C.H.; Li, J. Dimensionality reduction of hyperspectral data using discrete wavelet transform feature extraction. IEEE Trans. Geosci. Remote Sens. 2002, 40, 2331-2338.

37. Kingsbury, N. Image processing with complex wavelets. Philos. Trans. R. Soc. Lond. B Biol. Sci. 1999, 357, 2543-2560.

38. Koger, C.H.; Bruce, L.M.; Shaw, D.R.; Reddy, K.N. Wavelet analysis of hyperspectral reflectance data for detecting pitted morningglory (Ipomoea lacunosa) in soybean (Glycine max). Remote Sens. Environ. 2003, 86, 108-119. 
39. $\mathrm{Pu}, \mathrm{R}$.; Gong, P. Wavelet transform applied to EO-1 hyperspectral data for forest LAI and crown closure mapping. Remote Sens. Environ. 2004, 91, 212-224.

40. Blackburn, G.A. Wavelet decomposition of hyperspectral data: A novel approach to quantifying pigment concentrations in vegetation. Int. J. Remote Sens. 2007, 28, 2831-2855.

41. Zhang, J.; Lu, J. Feeding ecology of two wintering geese species at Poyang Lake, China. J. Freshw. Ecol. 1999, 14, 439-445.

42. Luo, M.; Li, J.; Cao, W.; Wang, M. Study of heavy metal speciation in branch sediments of Poyang Lake. J. Environ. Sci. 2008, 20, 161-166.

43. Uddling, J.; Gelang-Alfredsson, J.; Piikki, K.; Pleijel, H. Evaluating the relationship between leaf chlorophyll concentration and SPAD-502 chlorophyll meter readings. Photosynth. Res. 2007, 91, $37-46$.

44. Tokalioğlu, Ş.; Kartal, Ş.; Elci, L. Determination of heavy metals and their speciation in lake sediments by flame atomic absorption spectrometry after a four-stage sequential extraction procedure. Anal. Chim. Acta 2000, 413, 33-40.

45. Rafiee, J.; Tse, P.; Harifi, A.; Sadeghi, M. A novel technique for selecting mother wavelet function using an intelligent fault diagnosis system. Expert Syst. Appl. 2009, 36, 4862-4875.

46. Lhermitte, S.; Verbesselt, J.; Verstraeten, W.; Coppin, P. A comparison of time series similarity measures for classification and change detection of ecosystem dynamics. Remote Sens. Environ. 2011, 115, 3129-3152.

47. Rondeaux, G.; Steven, M.; Baret, F. Optimization of soil-adjusted vegetation indices. Remote Sens. Environ. 1996, 55, 95-107.

48. Williams, P. Near-Infrared Technology: Getting the Best Out of Light: A Short Course in the Practical Implementation of Near-Infrared Spectroscopy for the User; Value Added Wheat CRC: Sydney, NSW, Australia, 2004.

49. Saeys, W.; Mouazen, A.M.; Ramon, H. Potential for onsite and online analysis of pig manure using visible and near infrared reflectance spectroscopy. Biosyst. Eng. 2005, 91, 393-402.

(C) 2015 by the authors; licensee MDPI, Basel, Switzerland. This article is an open access article distributed under the terms and conditions of the Creative Commons Attribution license (http://creativecommons.org/licenses/by/4.0/). 